\title{
Environmental Impacts of Wind Energy
}

\author{
Suaad Jaber
}

\begin{abstract}
Man has harnessed the energy in wind for thousands of years, both for sailing boats and powering wind mills at land. Of all renewable energy sources, wind power is the most mature in terms of commercial development. This energy source is interesting because of its renewability and its availability. Potential for development is huge, and the world's capacity is far larger than the world's total energy consumption. Worldwide, a total capacity of about $60000 \mathrm{MW}$ have been installed, with a yearly production of about 100 TWh. The major challenges for further development are connected to economy, land usage, environment and grid capacity. The growth of renewable energy has been unprecedented over the past 25 years. Wind and solar have maintained double-digit growth rates since 2000 . No other segment of the energy sector has grown this fast. Wind power is the most economic new power plant technology, due to reduced installations costs, no fuel costs and construction time of less than one year, compared to over 10 years to construct nuclear power plants. The effects of wind energy on the environment often are considered to be positive, through the production of renewable energy and the potential displacement of mining activities, air pollution, and greenhouse gas emissions associated with non-renewable energy sources. As a result, a more complete understanding of the environmental and economic effects of any one energy source depends on a more complete understanding of how that energy source displaces or is displaced by other energy sources, and it depends on a more complete understanding of the environmental and economic effects of all other available energy sources. This paper provides analyses to understand those environmental effects, both positive and negative.
\end{abstract}

Index Terms-Environmental effects ecological impacts, renewable energy, wind energy.

\section{INTRODUCTION [1]}

In recent years, the growth of capacity to generate electricity from wind energy has been extremely rapid, To the degree that wind energy reduces the need for electricity generation using other sources of energy, it can reduce the adverse environmental impacts of those sources, such as production of atmospheric and water pollution, including greenhouse gases; production of nuclear wastes; degradation of landscapes due to mining activity; and damming of rivers. Generation of electricity by wind energy has the potential to reduce environmental impacts, because unlike generators that use fossil fuel, it does not result in the generation of atmospheric contaminants or thermal pollution, and it has been attractive to many governments, organizations, and individuals. But others have focused on adverse environmental impacts of wind-energy facilities, which include visual and other impacts on humans; and effects on

Manuscript received December 5, 2013; revised February 6, 2013.

Suaad Jaber is with Institute of Urban and Regional Planning for Postgraduate studies, Baghdad University, Irap (email: j_suaad@yahoo.com). ecosystems, including the killing of wildlife, especially birds and bats, some environmental effects of wind-energy facilities, especially those concerning transportation.

\section{RENEWABLE ENERGY}

Presently, the known alternatives to energy production from fossil fuels are renewable and nuclear energy. There exist many social and environmental complications with nuclear energy. Renewable energy sources are desirable because of their contribution to greenhouse gas reduction and national security of energy supply without the complications of nuclear energy. Formal definitions of renewable energy sources vary from country to country, but there is broad agreement that wind energy, photovoltaic, and solar thermal energy is considered to be renewables. Other sources that are often considered renewable include hydropower and biomass. Increasing dependence on renewable energy sources is complicated by various barriers to implementation. Most renewable energy technologies face cost disadvantages in comparison with conventional energy technologies. (Roads to and from the plant site) and transmission (roads and clearings for transmission lines), are common to all electricity-generating facilities; others, such as their specific aesthetic impacts, are unique to windenergy facilities, at regional to global scales.

\section{WIND ENERGY}

Wind power is a relatively mature technology. It competes with other energy sources in terms of price, environmental effects and usability. With the exception of hydro power, wind power is closer to commercial profitability than any of the other renewable sources, though improved project economy is a vital challenge for wind power [2]. Wind energy is widely applicable because wind resources are available in most countries. Among the renewable energy technologies, wind energy is relatively mature and many countries have resolved cost and technology challenges [3].

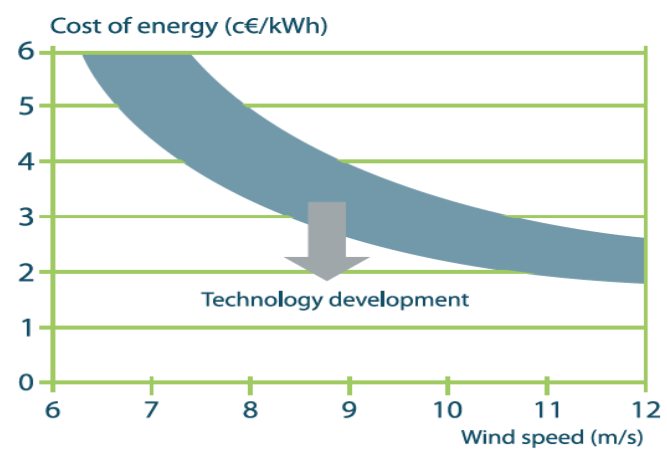

Fig. 1. Cost of wind power related to annual mean wind speed. Source: SINTEF Centre for Energy Research 
Wind is clean, free, indigenous and inexhaustible. Wind turbines do not need any type of fuel, so there are no environmental risks or degradation from the exploration, extraction, transport, shipment, processing or disposal of fuel. Not only is generation produced with zero emissions of carbon dioxide (during the operational phase) but it also does not release toxic pollutants (for example mercury) or conventional air pollutants (for example smog-forming nitrogen dioxide and acid rain-forming sulphur dioxide) [4].Wind energy projects must be located in accordance with the Planning Act, the regional plans, and the municipal plans. The regional plans provide general locations for wind projects and guidelines for integrating wind turbines with other land-uses. The municipal plans can include targets and desires related to wind energy and provide a more detailed basis for turbine location, number, height and appearance [5]. Wind energy is a clean and environmentally friendly technology that produces electricity. Its renewable character and the fact it does not pollute during the operational phase makes it one of the most promising energy systems for reducing environmental problems at both global and local levels.

\section{ENVIRONMENTAL IMPACTS OF WIND ENERGY}

Operation of wind power has zero emissions of harmful substances. It does not add to global warming, the "fuel" is free, and is quite evenly distributed around the world. The energy needed to produce and install the turbine amounts to three months of turbine production. But, as with other sources of energy, wind power does have an environmental impact. The impact on wildlife is likely low compared to other forms of human and industrial activity. However, negative impacts on certain populations of sensitive species are possible, and efforts to mitigate these effects should be considered in the planning phase. wind energy, like any other industrial activity, may cause impacts on the environment which should be analyzed and mitigated [6].

\section{A. Environmental Benefits}

What are the advantages to the environment that is caused by wind energy?

Primarily, wind energy do not cause water or air emissions, and do not produce any kind of hazardous waste as well. Moreover, wind power does not make use of natural resources like oil, gas or cause and therefore will not cause damage to the environment through resource transportation and extraction and also do not need consequent amounts of water during operation [5].

Wind energy is not only a favorable electricity generation technology that reduces emissions (of other pollutants as well as $\mathrm{CO}_{2}, \mathrm{SO}_{2}$ and $\mathrm{NOx}$ ), it also avoids significant amounts of external costs of conventional fossil fuel-based electricity generation [6].

More and more use of wind energy should be made in order to prevent the problem of global warming.

Wind energy plants are considered a green power technology because it has only minor impacts on the environment. Wind energy plants produce no air pollutants or greenhouse gases [7].

Wind energy is an ideal renewable energy because:
- It is a pollution-free, infinitely sustainable form of energy

- It doesn't require fuel

- It doesn't create greenhouse gases

- It doesn't produce toxic or radioactive waste

\section{B. Disadvantages}

Any means of energy production impacts the environment in some way, and wind energy is no different. Like every other energy technology, wind power plants do have some effects on the environment. Wind turbines cause virtually no emissions during their operation and very little during their manufacture, installation, maintenance and removal. Compared to the environmental impact of traditional energy sources, the environmental impact of wind power is relatively minor.

Wind farms are often built on land that has already been impacted by land clearing. The vegetation clearing and ground disturbance required for wind farms is minimal compared with coal mines and coal-fired power stations [7]. If wind farms are decommissioned, the landscape can be returned to its previous condition.

The major challenge to using wind as a source of power is that the wind is intermittent and it does not always blow when electricity is needed. Wind energy cannot be stored (unless batteries are used); and not all winds can be harnessed to meet the timing of electricity demands [3].

Good wind sites are often located in remote locations, far from cities where the electricity is needed. Wind resource development may compete with other uses for the land and those alternative uses may be more highly valued than electricity generation [4]. Although wind power plants have relatively little impact on the environment compared to other conventional power plants, there is some concern over the noise produced by the rotor blades, aesthetic (visual) impacts, and sometimes birds have been killed by flying into the rotors. Most of these problems have been resolved or greatly reduced through technological development or by properly sitting wind plants.

To the extent that we understand how, when, and where wind-energy development most adversely affects organisms and their habitat, it will be possible to mitigate future impacts through careful sitting decisions.

\section{ECOLOGICAL IMPACTS}

There are two major ways that wind-energy development may influence ecosystem structure and functioningthrough direct impacts on individual organisms and through impacts on habitat structure and functioning. Environmental influences of wind-energy facilities can propagate across a wide range of spatial scales, from the location of a single turbine to landscapes, regions, and the planet, and a range of temporal scales from short-term noise to long-term influences on habitat structure and influences on presence of species [5]. The ecological influences of wind-energy facilities are complex, and can vary with spatial and temporal scale, location, season, weather, ecosystem type, species, and other factors. Moreover, many of the influences are likely cumulative and ecological influences can interact in complex ways at wind energy facilities and at other sites 
associated with changed land-use practices and other anthropogenic disturbances [4]. Wind turbines cause fatalities of birds and bats through collision, most likely with the turbine blades. Species differ in their vulnerability to collision, in the likelihood that fatalities will have large scale cumulative impacts on biotic communities, and in the extent to which their fatalities are discovered [7]. the data are inadequate to assess relative risk to passerines and other small birds. It is possible that as turbines become larger and reach higher, the risk to the more abundant bats and nocturnally migrating passerines at these altitudes will increase [1]. Determining the effect of turbine size on avian risk will require more data from direct comparison of fatalities from a range of turbine types. The construction and maintenance of wind-energy facilities also alter ecosystem structure through vegetation clearing, soil disruption and potential for erosion, and noise. Alteration of vegetation, including forest clearing, represents perhaps the most significant potential change through fragmentation and loss of habitat for some species [6].Changes in forest structure and the creation of openings alter microclimate and increase the amount of forest edge. Plants and animals throughout an ecosystem respond differently to these changes. There might also be important interactions between habitat alteration and the risk of fatalities, such as bat foraging behavior near turbines [6].

Standardized studies should be conducted before sitting and construction and after construction of wind-energy facilities to evaluate the potential and realized ecological impacts of wind development [3]. Pre-sitting studies should evaluate the potential for impacts to occur and the possible cumulative impacts in the context of other sites being developed or proposed. Likely impacts could be evaluated relative to other potentially developable sites or from an absolute perspective. In addition, the studies should evaluate a selected site to determine whether alternative facility designs would reduce potential environmental impacts. Post-construction studies should focus on evaluating impacts, actual versus predicted risk, causal mechanisms of impact, and potential mitigation measures to reduce risk and reclamation of disturbed sites.

\section{IMPACTS ON HUMANS}

The human impacts include aesthetic impacts; impacts on cultural resources, such as historic, sacred, archeological, and recreation sites; impacts on human health and wellbeing, specifically from noise and from shadow flicker; economic and fiscal impacts; and the potential for electromagnetic interference with television and radio broadcasting, cellular phones, and radar. This is not an exhaustive list of all possible human impacts from wind-energy projects [6].

\section{CUltural IMPACTS [6]}

Wind-energy facilities create both positive and negative recreational impacts. On the positive side, many windenergy projects are listed as tourist sights: some offer tours or provide information areas about the facility and wind energy in general; and several are considering incorporating visitor centers. There are two types of potential negative impacts on recreational opportunities: direct and indirect. Direct impacts can result when existing recreational activities are either precluded or require rerouting around a wind-energy facility. Indirect impacts include aesthetic impacts (addressed above) that may affect the recreational experience. These impacts can occur when scenic or natural values are critical to the recreational experience. In analyzing impacts on historic, sacred, and archeological sites, the primary concern is that no permanent harm should be done that would affect the integrity of the site. Whether or not a wind-energy project would damage the resource may depend on the specific nature of the historic resources involved.

Unlike housing developments, wind-energy projects cannot be screened from view, except behind intervening topography and vegetation. Such issues are likely to arise as wind projects are proposed in cultural landscapes, and guidance as to what constitutes an undue impact to historic or sacred sites and areas will be necessary.

\section{IMPACTS ON Human HEALth [6]}

Wind-energy projects can have positive as well as negative impacts on human health and wellbeing. The positive impacts accrue mainly through improvements in air quality, as discussed previously in this report. These positive impacts (i.e., benefits) to health and well-being are diffuse; they are experienced by people living in areas where conventional methods of electricity generation are used less because wind energy can be substituted in the regional market. In contrast, to the extent that wind-energy projects create negative impacts on human health and wellbeing, the impacts are experienced mainly by people living near wind turbines that are affected by noise and shadow flicker.

\section{LOCAL ECONOMIC IMPACTS}

Wind-energy projects can have a range of economic and fiscal impacts, both positive and negative. Some of those impacts are experienced at the national or regional level; these involve, and for example, tax credits and other monetary incentives to encourage wind-energy production, as well as effects of wind energy on regional energy pricing. In this section, the focus is on the local level: on private economic impacts, positive and negative, as well as on public revenues and costs [6].

\section{Visual Impact [4]}

Landscape perceptions and visual impacts are key environmental issues in determining wind farm applications related to wind energy development as landscape and visual impacts are by nature subjective and changing over time and location.

The characteristics of wind developments may cause landscape and visual effects. These characteristics include the turbines (size, height, number, material and color), access and site tracks, substation buildings, compounds, grid 
connection, anemometer masts, and transmission lines. Another characteristic of wind farms is that they are not permanent, so the area where the wind farm has been located can return to its original condition after the decommissioning phase. While visual impact is very specific to the site at a particular wind farm, several characteristics in the design and sitting of wind farms have been identified to minimize their potential visual impact

\section{NOISE IMPACT}

Noise from wind developments has been one of the most studied environmental impacts of this technology. Noise, compared to landscape and visual impacts, can be measured and predicted fairly easily.

As with any machine involving moving parts, wind turbines generate noise during operation. Noise from wind turbines arises mainly from two sources: 1) mechanical noise caused by the gearbox and generator; and 2) aerodynamic noise caused by interaction of the turbine blades with the wind [6].

Experience acquired in developing wind farms suggests that noise from wind turbines is generally very low [7]. The comparison between the number of noise complaints about wind farms and about other types of noise indicates that wind farm noise is a small-scale problem in absolute terms. Information from the US also suggests that complaints about noise from wind projects are rare and can usually be satisfactorily resolved.

\section{IMPACT ON LAND USE [4]}

National authorities consider the development of wind farms in their planning policies for wind energy projects.

Decisions on sitting should be made with consideration to other land users. Regional and local land-use planners must decide whether a project is compatible with existing and planned adjacent uses, whether it will modify negatively the overall character of the surrounding area, whether it will disrupt established communities, and whether it will be integrated into the existing landscape. Land use planning rules in some countries recommend avoiding areas with protected designations; in others, specific areas have been earmarked for potential wind farm development.

\section{Reduce the NeGATIVE EnVIRONMENTAL IMPACTS OF WIND ENERGY}

The negative environmental impacts from wind energy installations are much lower in intensity than those produced by conventional energies, but they still have to assessed and mitigated when necessary. There are specific conditions that must be in place before an area can be considered suitable for a wind farm development. These conditions include factors such as: wind climate, topographical, logistical and ecological constraints [5].

A strategic environmental assessment (SEA) is the procedure used to evaluate the adverse impacts of any plans and programs on the environment. National, regional and local governments must undertake SEAs of all wind energy plans and programs that have the potential for significant environmental effects [6]. The ecological influences of wind-energy facilities are complex, and can vary with spatial and temporal scale, location, season, weather, ecosystem type, species, and other factors. Moreover, many of the influences are likely cumulative and ecological influences can interact in complex ways at wind energy facilities and at other sites associated with changed land-use practices and other anthropogenic disturbances [5]. Because of this complexity, evaluating ecological influences of wind-energy development is challenging and relies on understanding factors that are inadequately studied. Despite this, several patterns are beginning to emerge from the information currently available. Increased research using rigorous scientific methods will be critical to filling existing information gaps and improving reliability of predictions.

In conclusion, we must decide that if we have to produce electricity, it is certainly preferable to produce it in a way which has the smallest possible impact on the environment. From a technical and economic standpoint, the most mature form of renewable and "clean" energy is wind energy. It can effectively contribute to combating climate change while at the same time providing various environmental, social and economic benefits. On the other hand, it is necessary to minimize the impact of the wind energy, particularly in terms of environment (preservation of protected areas) and human health (noise and visual impact).

\section{REFERENCES}

[1] Renewable energy. [Online]. Available: www.renewableenergy.no.

[2] D. Reiche and M. Bechnerger, "Policy differences in the promotion of renewable energies in the EU member states," Energy Policy, vol. 32, 2004.

[3] M. Wolsink, "Wind power and the NIMBY-myth: Institutional capacity and the limited significance of public support," Renewable Energy, vol. 21, 2000

[4] Wind energy - the facts, part $\mathrm{V}$ environmental issues. [Online]. Available: www.wind-energy-the-facts.org/documents/download /Chapter5.pdf

[5] N. Miles and K. Odell, "Spatial planning for wind energy: Lessons from the Danish case," Department of environment, Technology and Social studies, Roskilde University's center.

[6] Environmental Impacts of Wind-Energy Projects- Committee on Environmental Impacts Of wind energy Projects board on environment Studies and Toxicology Division on Earth and Life Studies the national academies press. Washington D.C. [Online]. Available: www.nap.edu. [Online]. Available: http://en.wikipedia.org/wiki/Environmental_impact_of_wind_power

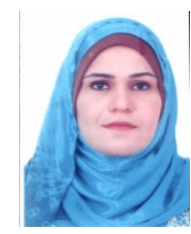

Suaad Jabber Laffta was born in Aug. 16, 1972 in Iraq. Her Specific Specialty: environmental planning, environmental \& sustainable assessment. She has been working as a faculty member in the Institute of Urban and Regional Planning for Postgraduate studies,. University of Baghdad since 2001, graduated from the surveying Eng Dept - University of Baghdad in 1994.

She took her master degree in urban studies from the Higher Institute of Urban \& Regional Planning, University of Baghdad, 2006. AT the present time she a Doctoral student in the Institute of Urban and Regional Planning for Postgraduate studies, University of Baghdad. 